\title{
Buildings as sources of mercury to the atmosphere
}

\author{
G. F. M. Tan ${ }^{1}$, E. Cairnsa ${ }^{1}$, K. Tharumakulasingam ${ }^{1}$, \\ J. $\mathrm{Lu}^{1} \&$ D. Yap ${ }^{2}$ \\ ${ }^{I}$ Department of Chemistry and Biology, Ryerson University, Canada \\ ${ }^{2}$ Ontario Ministry of the Environment, Canada
}

\begin{abstract}
Atmospheric gaseous elemental mercury (GEM) on the streets in the city core at various heights above ground, in parking lots, and in indoor and outdoor air was measured in Toronto, the largest city in Canada. The GEM in the indoor air ranged from 1.15-258.4 (average $12.54 \pm 11.26$ ) $\mathrm{ng} \mathrm{m}^{-3}$ and was much higher than that in the outdoor air (average $1.89 \pm 0.49$ ). The average GEM in underground parking lots ranged from $1.37-7.86 \mathrm{ng} \mathrm{m}^{-3}$ and was higher than those observed from the surface parking lots. The GEM values increased with increasing elevation and increasing distance from building walls. All of these findings suggest that mercury used in the indoor environment has been diffused and emitted to the outdoor environment, thus, the buildings serve as sources of mercury of GEM to the urban atmosphere. More studies are needed to estimate the contribution of urban areas to the atmospheric $\mathrm{Hg}$ budget and the impact of indoor air on outdoor air quality and human health.

Keywords: gaseous elemental mercury, urban atmosphere, source of emission, depth profiling, Toronto.
\end{abstract}

\section{Introduction}

Mercury $(\mathrm{Hg})$ is a persistent and highly toxic element (Sarikaya et al. [1]). It can be emitted from natural and anthropogenic sources, largely as gaseous elemental mercury (GEM) (Bagnato et al. [2]; Song et al. [3]; Goodarzi [4]). The atmosphere receives most of the mercury emitted from these sources (Goodarzi [4]), thus, it is the major pathway of transporting this toxic element. Elemental 
$\mathrm{Hg}$ has an atmospheric lifetime of around one year (Schroeder and Munthe [5]), therefore, it is considered a true global pollutant.

Due to its unique physical and chemical properties, $\mathrm{Hg}$ has been widely used in industry (e.g., in electrical equipment and control devices, in the electrolytic preparation of chlorine and alkalis), in agriculture (e.g., as pesticides, fungicides, and bactericides), in dental practices, in pharmaceuticals, and in daily products such as thermometers, barometers, bulbs, batteries, paints, and cosmetic products etc. All the above-listed processes and uses are concentrated in cities. They, therefore, in turn, are sources of mercury to the environment. Limited studies have indeed shown higher atmospheric mercury in urban areas (Witt et al. [6]; St. Denis et al. [7]; Carpi and Chen [8]; Liu et al. [9]) and the concentrations of GEM in urban atmosphere varied with variation of urban structure and height (Song et al. [3]; St. Denis et al. [7]; Carpi and Chen [8]). Our studies showed that local sources which have neither been identified nor been reported in the Canadian National Pollutant Release Inventory (NPRI) might have contributed to the high levels of atmospheric $\mathrm{Hg}$ in Toronto (Cheng et al. [10]) and that the higher GEM concentration values were more concentrated in the city core and emissions from vehicles and ground surfaces in the city were not the major sources of GEM to the urban atmosphere (Cairns et al. [11]).

\section{Experimental}

\subsection{Experimental location}

The experiments were carried out in the City of Toronto (population 2.5 million), Ontario, Canada. The site locations are shown in Fig. 1. According to the NPRI Environment Canada [12], there is no source of $\mathrm{Hg}$ (cut-off level of $5 \mathrm{~kg}$ ) in the city area.

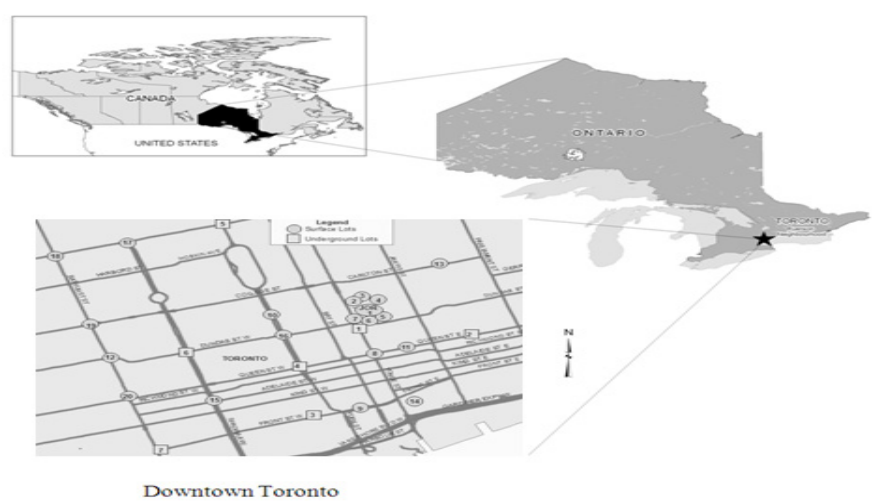

Figure 1: Experimental locations. 


\subsection{Instrumental}

Atmospheric GEM was measured along the major streets and at surface and underground parking lots in the city, using a mercury vapour analyzer (Model 2537A, Tekran Inc., Toronto, Canada). The analyzer has a built-in air pump for air sampling and employs dual gold cartridges, arranged in parallel, for $\mathrm{Hg}$ preconcentration, thus, allowing continuous measurements of mercury in the air samples. After every 2.5 -minute pre-concentration period, mercury is thermally desorbed from the gold cartridges and determined using cold vapour atomic fluorescence spectrometry (CVAFS). Since the particulate matter in the air stream was removed by a front-end Teflon filter before it entered the analyzer, it is widely accepted that the analyzer measures GEM in the air sample. The analyzer was calibrated automatically through a built-in permeation mercury source every 23 hours. The permeation mercury source was verified by manual injection before and after the field campaign. The internal permeation source provided approximately $1 \mathrm{pg} \mathrm{s}^{-1}$ of gaseous elemental mercury $\left(\mathrm{Hg}^{0}\right)$ at $50^{\circ} \mathrm{C}$ into a zero air stream, whereas the manual calibration was done by injecting a certain volume of air saturated with mercury vapour at a known temperature from a mercury vapour calibration unit (Tekran Inc., model 2505, Toronto). The average detection limit was about $0.1 \mathrm{ng} \mathrm{m}^{-3}$ for GEM.

\subsection{Method}

During the street measurement period, the analyzer was installed on board of a minivan with two inlets: one was hanging over the dashboard glass using a pole that was held on the rooftop of the van and was about $1.8 \mathrm{~m}$ above ground (i.e., at pedestrian level); the other was attached to a pole that extended about $4 \mathrm{~m}$ above ground. While driving along the streets, and highways and parking underground, only the $1.8 \mathrm{~m}$-inlet was used. A global positioning system (GPS) was used to track the locations of the analyzer. While parked at some of the surface lots, air was sampled from the two inlets in an alternative fashion. A second mercury analyzer, which was a part of the mercury speciation monitoring system, was running on the rooftop of Jorgensen Hall (JOR), Fig.1, which is $\sim 59 \mathrm{~m}$ above ground. Accordingly, while the van was parked around JOR, GEM was measured from three levels: $1.8 \mathrm{~m}, 4 \mathrm{~m}$, and $59 \mathrm{~m}$ above ground. Rooms with different usage types (e.g. research labs and office) were selected for the measurements of GEM in indoor and outdoor air. These rooms are located in the north and east sides of a square-shaped building (Kerr Hall, $\sim 160 \mathrm{~m}$ long) with a courtyard in the middle. During the experiments, the pump in the analyzer pulled air in from inside and outside (using Teflon tubing through a window) 1,3 , and $6 \mathrm{~m}$ away from the wall in an alternative order for each room tested.

\section{Results and discussion}

\subsection{GEM at surface parking vs. underground parking}

The results from the (20) surface parking (at $1.8 \mathrm{~m}$ ) and the (7) underground parking lots are presented in Fig. 2. The average GEM value for the surface sites 
ranged from $1.31-3.90 \mathrm{ng} \mathrm{m}^{-3}$ with an overall mean value of $1.89 \pm 0.35 \mathrm{ng} \mathrm{m}^{-3}$. The overall mean value agreed well with the overall pedestrian level GEM (1.89 $\pm 0.62 \mathrm{ng} \mathrm{m}^{-3}$ ) from driving measurements reported by Cairns et al. [11], suggesting that the movement speed of the analyzer had no significant effect on the measured GEM values. The mean value for the underground sites ranged from 1.37-7.86 $\mathrm{ng} \mathrm{m}^{-3}$. Values higher than the mean value from surface parking $\left(1.88 \pm 0.35 \mathrm{ng} \mathrm{m}^{-3}\right)$ were observed in 4 out of the 7 underground parking lots visited and the average value $\left(3.45 \pm 0.99 \mathrm{ng} \mathrm{m}^{-3}\right)$ was statistically significantly higher than that from surface parking lots. The highest GEM value (average 7.86

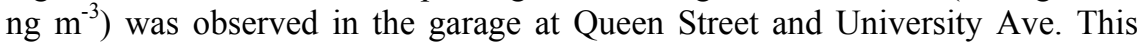
garage was revisited on a different day and the observed average GEM value $\left(1.92 \mathrm{ng} \mathrm{m}^{-3}\right)$ this time was much lower. This suggests that some local sources had contributed to the high GEM value and these sources were not consistent.

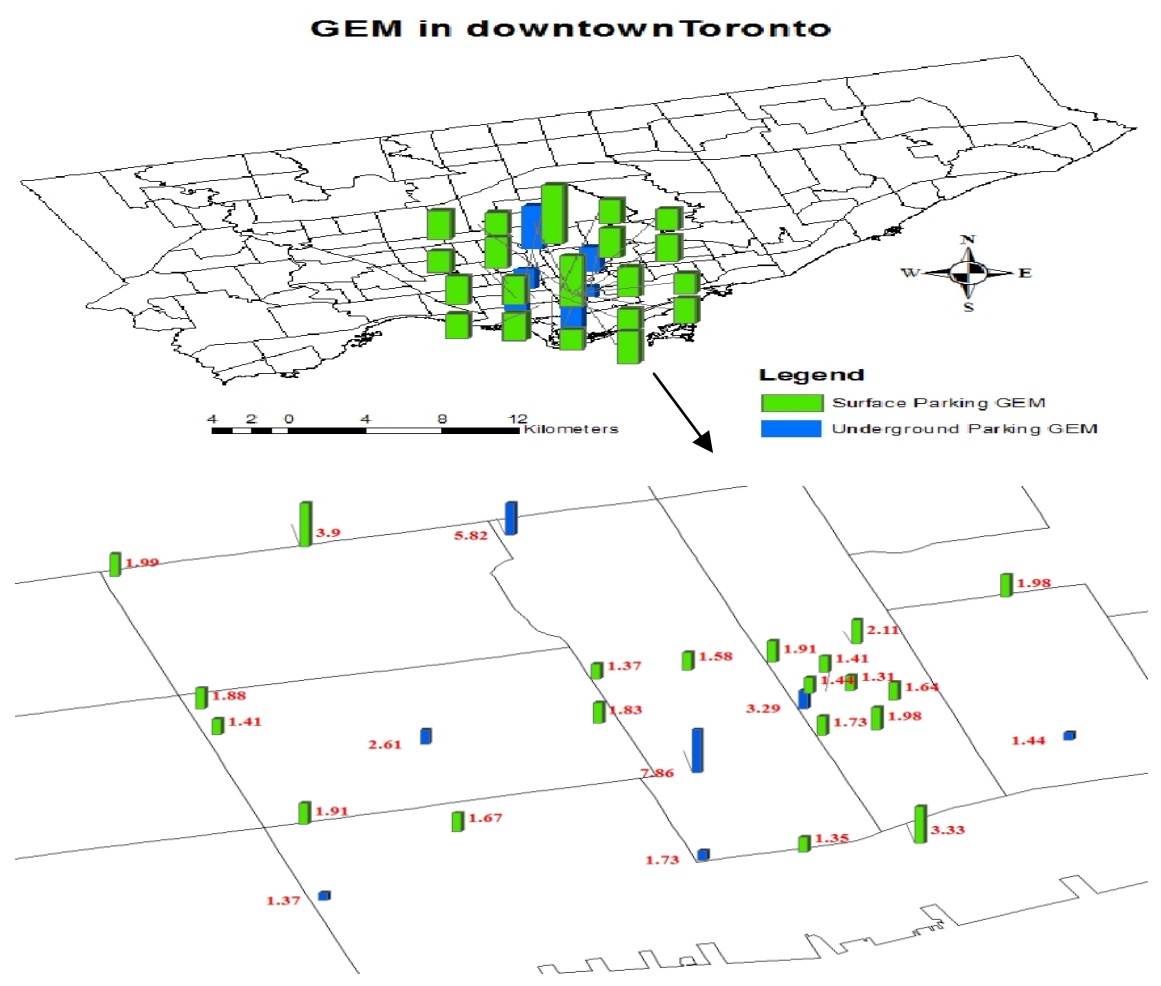

Figure 2: Comparison of atmospheric GEM concentrations measured at surface and underground parking lots in downtown Toronto.

\subsection{GEM indoor vs. outdoor}

Table 1 lists the concentrations of atmospheric GEM observed from both indoor and outdoor. The indoor GEM was measured inside (1) an office in the $1^{\text {st }}$ floor, 
(2) a research lab in the $2^{\text {nd }}$ floor (Lab 1) and (3) a research lab in the $3^{\text {rd }}$ floor (Lab 2). The outdoor GEM was measured on the streets within downtown Toronto. Lab 1 is relatively older and larger than Lab 2 and has chemical storage and laboratory equipments. An average of $17.70 \pm 22.44 \mathrm{ng} \mathrm{m}^{-3}$ (ranging from $3.28-258.4 \mathrm{ng} \mathrm{m}^{-3}$ ) GEM was observed in Lab 1 . This was approximately 4 times higher than Lab $2\left(4.51 \pm 3.48 \mathrm{ng} \mathrm{m}^{-3}\right.$, ranging from $\left.1.15-25.75 \mathrm{ng} \mathrm{m}^{-3}\right)$ and was comparable to GEM level inside the office $\left(15.42 \pm 7.86 \mathrm{ng} \mathrm{m}^{-3}\right.$, ranging from $\left.2.19-40.83 \mathrm{ng} \mathrm{m}^{-3}\right)$. The presence of chemicals and reagents containing $\mathrm{Hg}$ (e.g., $\mathrm{Hg}$ standards, $\mathrm{HgCl}_{2}, \mathrm{HgBr}$ etc.) in Lab 1 might have contributed to the higher indoor GEM level as compared to Lab 2 and office. In addition, huge spikes $\left(109.5-258.4 \mathrm{ng} \mathrm{m}^{-3}\right)$ were observed in Lab 1 when the ventilation unit inside the room was displaced, indicating the possibility of $\mathrm{Hg}$ accumulation on the ventilation unit over time. A lower ventilation rate, as observed physically, in Lab 1 compared to Lab 2, could be the other contributing factor to the elevated GEM levels. The office GEM was lower than Lab 1 but higher than Lab 2. The absence of a ventilation unit inside the office might have contributed to this variation, thus, indicating the importance of ventilations in maintaining good air quality. Overall, the average GEM level indoor $\left(12.54 \pm 11.26 \mathrm{ng} \mathrm{m}^{-3}\right)$ was approximately 7 times higher than that in outdoor $\left(1.89 \pm 0.46 \mathrm{ng} \mathrm{m}^{-3}\right)$. Similar result with higher indoor GEM compared to outdoor was observed by Li et al. [13].

Table 1: Comparison of atmospheric GEM measured at both indoor and outdoor areas.

\begin{tabular}{llll}
\hline $\begin{array}{l}\text { Type } \\
\text { Outdoor }\end{array}$ & $\begin{array}{l}\text { Number of } \\
\text { Measurements }\end{array}$ & Range & $\begin{array}{l}\text { Mean } \pm \text { Std. } \\
\text { Dev. }\end{array}$ \\
Driving & 2147 & $1.06-8.25$ & $1.89 \pm 0.62$ \\
Surface parking & 722 & $0.24-7.07$ & $1.89 \pm 0.35$ \\
$\quad$ Overall & 2869 & $0.24-8.25$ & $1.89 \pm 0.49$ \\
Indoor & & & \\
Office & 244 & $2.19-40.83$ & $15.42 \pm 7.86$ \\
Lab 1 & 950 & $3.28-258.4$ & $17.70 \pm 22.44$ \\
Lab 2 & 834 & $1.15-25.75$ & $4.51 \pm 3.48$ \\
Overall & 2028 & $1.15-258.4$ & $12.54 \pm 11.26$ \\
\hline
\end{tabular}

\subsection{GEM horizontal profile}

Fig. 3 shows the comparison of the data collected indoor and outdoor at a distance of $1 \mathrm{~m}, 3 \mathrm{~m}$, and $6 \mathrm{~m}$ away from the building wall. The results obtained from $1 \mathrm{~m}, 3 \mathrm{~m}$, and $6 \mathrm{~m}$ away from the building wall have an average of $3.48( \pm$ 1.36) $\mathrm{ng} \mathrm{m}^{-3}, 3.48( \pm 1.33) \mathrm{ng} \mathrm{m}^{-3}$, and $3.15( \pm 1.10) \mathrm{ng} \mathrm{m}^{-3}$ from the office, respectively; $3.57( \pm 2.18) \mathrm{ng} \mathrm{m}^{-3}, 3.40( \pm 2.51) \mathrm{ng} \mathrm{m}^{-3}$, and $3.64( \pm 2.93) \mathrm{ng} \mathrm{m}^{-3}$, from Lab 1, respectively; and $3.17( \pm 2.35) \mathrm{ng} \mathrm{m}^{-3}, 4.16( \pm 4.02) \mathrm{ng} \mathrm{m}^{-3}$, and 
$4.94( \pm 2.64) \mathrm{ng} \mathrm{m}^{-3}$ from Lab 2, respectively. The GEM concentration values decreased with increasing distance from the building wall outside of the office. For the results from the labs, a trend of decreasing then increasing concentration of GEM was observed the further the sampling location is from the wall. Analysis shows that the results from all the locations (office and labs) are statistically significantly different from one another, with a confidence level of $99 \%$. The tree branches near the labs could have prevented air from well mixing, as the air sampling inlets were supported using tree branches located closed to the buildings, thus, requiring further investigation. All the values observed in the air $6 \mathrm{~m}$ away from the building walls were higher than the value observed from surface parking, indicating the effect of further dilution.

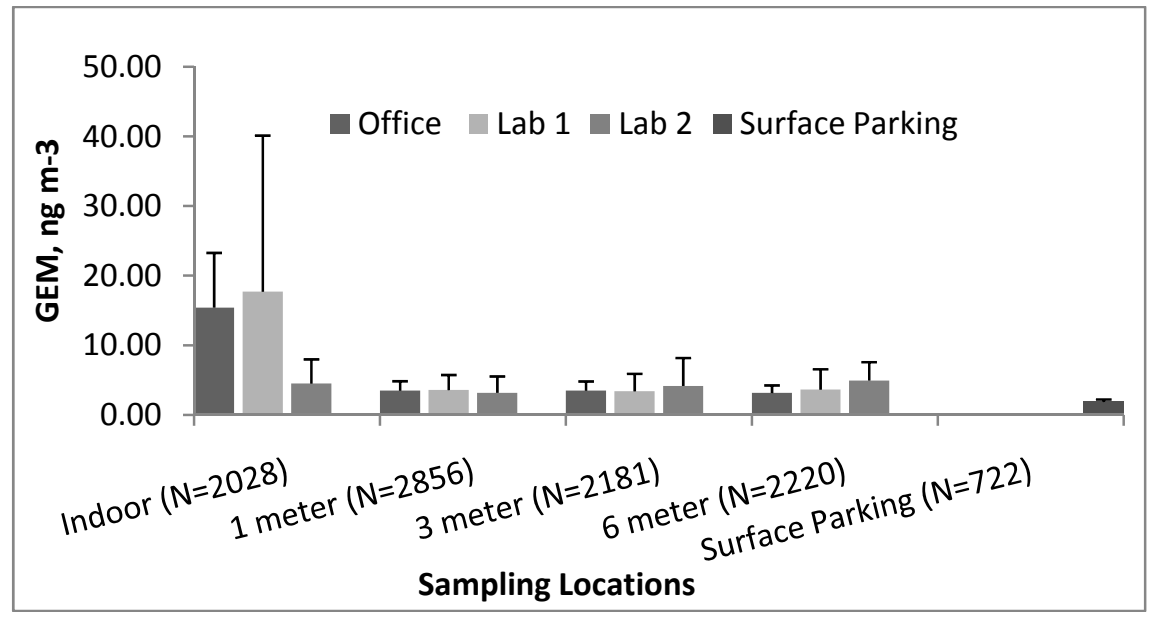

Figure 3: Comparison of atmospheric GEM concentrations measured indoor and outdoor 1, 3, and 6m away from the building wall and from streets.

\subsection{GEM depth profile}

Fig. 4 shows the statistical analysis of the data collected at $1.8 \mathrm{~m}, 4 \mathrm{~m}$, and $59 \mathrm{~m}$ from 7 sites around Jorgenson Hall in the city core. The GEM values ranged from $1.25-1.75 \mathrm{ng} \mathrm{m}^{-3}$ (average $1.44 \pm 0.19$ ), $1.30-1.80$ (average $1.48 \pm 0.18$ ), and 2.60-3.70 (average $3.09 \pm 0.47$ ) $\mathrm{ng} \mathrm{m}^{-3}$ for the $1.8 \mathrm{~m}, 4 \mathrm{~m}$, and $59 \mathrm{~m}$ level, respectively. A comparison of the values observed at the three levels showed that the higher the elevation, the higher the GEM concentrations were. The values from the 1.8 and $4 \mathrm{~m}$ agree well with those obtained from other locations in the city at the same height Cairns et al. [11]. This suggests that buildings serve as sources of GEM to the atmosphere, as if GEM were emitted from the ground surface and vehicles, the GEM concentration should be, due to the dilution effect, lower at higher elevation. 


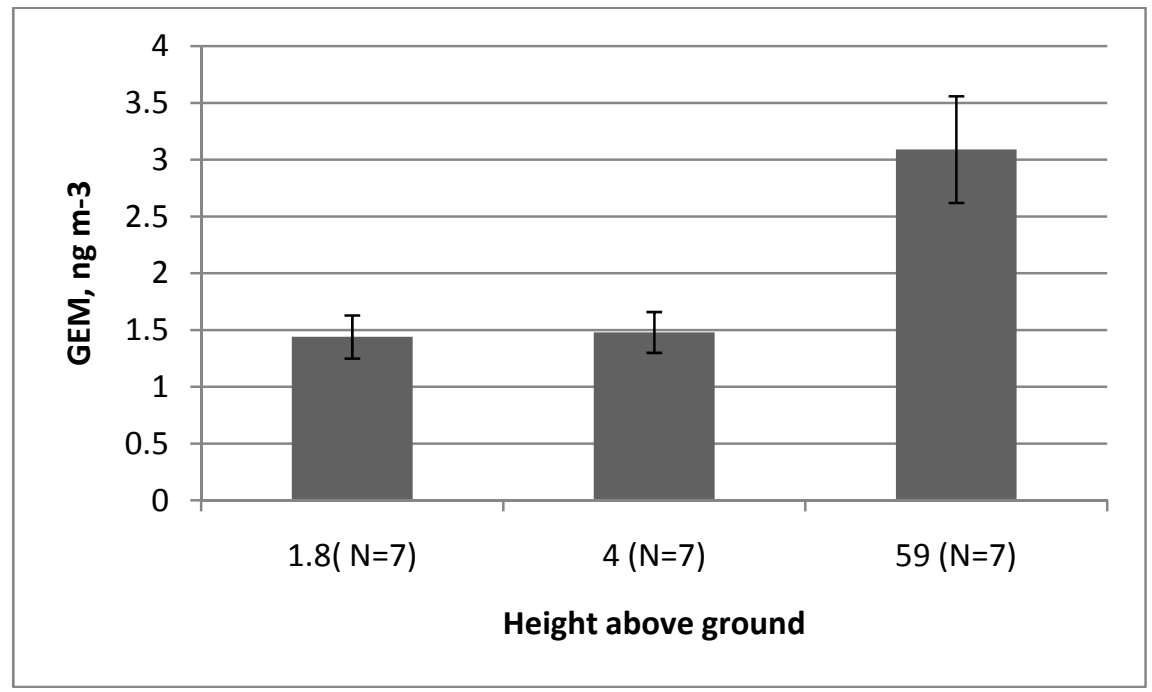

Figure 4: Three-Level (1.8, 4 and 59m above ground) depth profiles of GEM around Jorgenson Hall in downtown Toronto, May-July 2009. $\mathrm{N}=$ number of sites.

\section{Conclusion}

The results from this study showed that, in Toronto, Canada, (1) the higher the elevation, the higher the atmospheric GEM values were in the street canyon; (2) GEM levels were higher in the underground parking lots than those at the surface parking lots; (3) GEM levels were higher indoors as compared to outdoors. All of these findings suggest that mercury used in the indoor environment has been diffused and emitted to the outdoor environment, thus the buildings serve as sources of mercury and that emission from vehicles and ground surfaces were not the major sources of GEM to the urban atmosphere.

\section{Acknowledgements}

The Ontario Ministry of Environment (MOE) and Natural Sciences and Engineering Research Council (NSERC) of Canada for financial support.

\section{References}

[1] Sarikaya, S., Karcioglu, O., Ay, D., Cetin, A., Aktas, C., Serinken, M., Acute mercury poisoning: a case report. BMC Emergency Medicine 10, 7, 2010. 
[2] Bagnato, E., Allard, P., Parello, F., Aiuppa, A., Calabrese, S., Hammouya, G., Mercury gas emissions from La Soufriere Volcano, Guadeloupe Island (Lesser Antilles). Chemical Geology 266, 276-282, 2009.

[3] Song, X., Cheng, I., Lu, J., Annual atmospheric mercury species in Downtown Toronto, Canada , Journal of Environmental Monitoring 11, 660-669, 2009.

[4] Goodarzi, F., Speciation and mass-balance of mercury from pulverized coal fired power plants burning western Canadian subbituminous coals. Journal of Environmental Monitoring 6, 792-798, 2004.

[5] Schroeder, W.H., Munthe, J., Atmospheric mercury - an overview. Atmospheric Environment 32 (5), 809-822, 1998.

[6] Witt, M.L.I., Meheran, N., Mather, T.A., de Hoog, J.C.M., Pyle, D.M., Aerosol trace metals, particle morphology and total gaseous mercury in the atmosphere of Oxford, UK. Atmospheric Environment 44, 1524-1538, 2010.

[7] St. Denis, M., Song, X., Lu, J., Feng, F., Atmospheric gaseous elemental mercury in downtown Toronto. Atmospheric Environment 40, 4016-4024, 2006.

[8] Carpi, A., Chen, Y. F., Gaseous elemental mercury fluxes in New York City. Water Air and Soil Pollution 140, 371-379, 2002.

[9] Liu, S.L., Nadim, F., Perkins, C., Carley, R.J., Hoag, G.E., Lin, Y.H., Chen, L.T., Atmospheric mercury monitoring survey in Beijing, China. Chemosphere 48, 97-107, 2002.

[10] Cheng, I., Lu, J., Song, X., Studies of potential sources that contributed to atmospheric mercury in Toronto, Canada. Atmospheric Environment 43, 6145-6158, 2009.

[11] Cairns, E., Tharumakulasingam, K., Athar, M., Yousaf, M., Cheng I., Huang Y., Lu J., Yap D., Source, concentration, and distribution of elemental mercury in the atmosphere in Toronto, Canada, Environmental Pollution, 2011.

[12] National Pollutant Release Inventory (NPRI). Environment Canada Website, Canada, <http://www.ec.gc.ca/inrp-npri/default.asp?lang $=$ En\&n=4A577BB9-1>

[13] Li, J., Yang, Y., Chen, H., Xiao, G., Wei, S., Sourcing contributions of gaseous mercury in indoor and outdoor air in China. Environmental Forensics 11, 154-160, 2010. 